

Open $\odot$ Access

Research Article

\title{
Development and Characterization of Barbaloin Gel for the Safe and Effective Treatment of Psoriasis
}

\author{
Singh Navdeep" ${ }^{1}$, Goyal Kamya², Sondhi Shivi', Jindal Shammy*1,3 \\ ${ }^{1}$ Department of Pharmaceutics, Laureate Institute of Pharmacy, Kathog, Jawalamukhi, Himachal Pradesh 176031, India \\ 2 Department of pharmaceutical Analysis and Chemistry, Laureate Institute of Pharmacy, Kathog, Jawalamukhi, Himachal Pradesh 176031, India \\ ${ }^{3}$ Research scholar, Department of Pharmaceutics, Amity Institute of Pharmacy, Amity University Uttar Pradesh, Sector-125, Noida 201303, \\ India
}

\begin{abstract}
Psoriasis is an inflammatory skin disease which cause inflammation to the skin and generally the symptoms includes white or red colour of irregular skin; the patches are developed and they are commonly itchy and scaly to the skin. Barbaloin is an herbal phytoconstituent which is obtained from the plant aloe vera leaf part. In the present study hydrogels formulation batches from F1 to F10 were prepared by using carbopol 934, Xanthan gum, carbopol 940, and carbopol 71G NF as a gelling agent. The prepared formulations from F1 to F10 were evaluated for their physical appearance, Grittiness, spreadability, Homogeneity, viscosity, $\mathrm{pH}$, swelling index and microscopical evaluation. The changes in each evaluation parameter were examined at multiples concentration of each polymer. The effects of gelling agent in each formulation were observed and it will help us to justify the suitable range of polymer as a single or in combination with other gelling agent. From these studies it was found to be formulation F2, F4, F7 and F10 showing good gelling properties and further these four formulations are selected for In Vitro drug release studies. By In Vitro drug release kinetics study formulation F2 and F10 showed higher release as compared to F4 and F7. Furthermore, formulation F2 and F7 had good kinetic release study and showed non fickian drug release as the n value was between 0.8-0.9. Therefore, from the above release study parameters formulation F2 and F10 show the best optimized release characterstics as compare to the selected optimized formulations F4 and F7.
\end{abstract}

Keywords: Psoriasis, Barbaloin, Hydrogel, Formulation and Evaluation.

Article Info: Received 17 July 2020; Review Completed 24 Aug 2020; $\quad$ Accepted 30 August 2020; Available online 15 September 2020

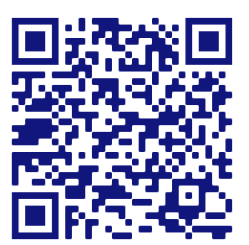

Cite this article as:

Singh N, Goyal K, Sondhi S, Jindal S, Development and Characterization of Barbaloin Gel for the Safe and Effective Treatment of Psoriasis, Journal of Drug Delivery and Therapeutics. 2020; 10(5):188-197

http://dx.doi.org/10.22270/jddt.v10i5.4299

*Address for Correspondence:

Shammy Jindal, Department of Pharmaceutics, Laureate Institute of Pharmacy, Kathog, Jawalamukhi, Himachal Pradesh 176031, India

\section{INTRODUCTION}

Psoriasis is an enduring autoimmune disease which causes inflammation to the skin. Psoriasis is categorized by different clinical manifestations and each class of psoriasis is characterized by examine the mild, moderate to severe symptoms on skin. These symptoms generally include the white or red colour of irregular skin; the patches are commonly itchy and scaly to the skin. ${ }^{1}$ Psoriasis skin is evaluated by itching, red scalps, white scales and rashes are developed on the skin. In psoriasis commonly the skin, joints and nails are affected. However, there are different clinical types of psoriasis are available, but the plaque type of psoriasis is the most common obtainable form of psoriasis which affect most of peoples worldwide. Psoriasis is a nonepidemic infectious disease and terrible skin disorder, which affects the person emotionally, psychologically and clinically.2, 3 In the study of (IFPA) International Federation of Psoriasis Associations, just about the $3 \%$ of the world's population has affected by psoriasis. The estimate is about 125 million peoples. ${ }^{4}$ In India, there is about 10 million cases of psoriasis are observed annually. So according to their increasing growth it enlists under common skin disorder, and at present it is important to doing more work for the treatment of psoriasis.

Nowadays, many treatments are available which include topical, biological, systemic agents are used. Some of the agents are helpful to reduce the symptoms of psoriasis but they have some side effects also. In the meantime it is important to develop the treatment with good efficacy and fewer side effects. As compare to allopathic agents the herbal drugs are safer and effective to reduce the symptoms of psoriasis. Because of their minimum adverse effects they are trending in the research. ${ }^{5}$ 
A phytoconstituent "Barbaloin" which is obtained from the plant aloe vera is used for the effective treatment of psoriasis. According to the investigation Patel DK et al., 2012 had revealed that Barbaloin shows good antiinflammatory, antimicrobial and antipsoriatic property. ${ }^{6}$ Barbaloin make use of their protective action mainly through antioxidant and antiinflammatory mechanisms. Hence, Barbaloin upregulated TFG $\beta 1, b F G F$, and Vegf-A expression in fibroblasts and increased keratinocyte proliferation and differentiation by lysosomal membrane stability. Additionally, Furthermore, Barbaloin exerted skin protection by reducing IL-8 production, DNA damage, lipid peroxidation, and ROS generation and by increasing GSH content and SOD activity. ${ }^{7}$

The aim of the present study is to formulate and evaluate Barbaloin hydrogel. The main function of hydrogels is to provide mechanical strength to the formulation and increase their swelling behavior. ${ }^{8}$ Their shape, stability and softness are similar with the soft neighboring tissues and they have good rheological properties and tissue compatibility. To achieve the objectives, formulation were prepared by suitable method and further the effect of each gelling agent in formulations was examined in terms of physical appearance, $\mathrm{pH}$, homogeneity, grittiness, viscosity, and spreadability and swelling index. The observed results were helps us to find the best optimized formulation of hydrogels. To find the diffusion mechanism of drug release the optimized formulations was interpreted by kinetics models.

\section{MATERIALS AND METHODS}

\section{Materials and Equipments}

Barbaloin was purchased from Yucca Enterprises Mumbai. India, Carbopol 934 and Carbopol 940 was purchased from SDFCL Mumbai, India, Xanthan gum and methyl paraben was purchased from Qualikems fine chemicals Pvt. Ltd. India, carbopol 71G NF, Glycerine, propylene glycol, Transcutol P, propyl paraben and triethanolamine were purchased from Central drug house Pvt. Ltd. New Delhi, India. Ethanol was purchased from HiMedia Laboratories Pvt. Ltd. 23 Badhani Ind. Est. LBS Marg Mumbai, India.

LAB INDIA 3000 model of UV-Visible Spectrophotometer was used, FTIR Spectrophotometer of Shimazadu Affinity-1 was used. Magnetic stirrer, Sonicator, hot air oven, digital melting point apparatus and digital $\mathrm{pH}$ meter of Rolex brand was used. The magnetic analytical balance of Wensar was used in experiment.

\section{Methods}

\section{Preformulation Study of Barbaloin}

\section{Physical description}

Drug was observed macroscopically with the help of hand held lens against black and white background. The observations were recorded to understand the physical appearance of Barbaloin.

\section{Determination of Melting Point}

Melting point of Barbaloin was examined by capillary method. A fine powder of Barbaloin was filled in the capillary tube (previously fused from one end) and then placed the capillary in digital melting point equipment. The temperature was visualized in digital display of meter, now with the increase of temperature the sample was converted into melting range, after that the melting range were noted down. ${ }^{9}$

\section{Partition Coefficient}

The partition coefficient is useful to find out the lipophilic and hydrophilic nature of drug. Shake flask method is used to determine the partition coefficient. In this method octanol was used as non-aquas phase and distilled water is used as aquas phase. Earlier than, the addition of drug, both phases were pre-saturated with each other. Equal quantities of each phase is taken in 1:1 $\mathrm{v} / \mathrm{v}$ ratio and shake the mixture of both phases overnight in a water bath shaker. After the complete mixing both the phases are separated from shake flask funnel and centrifuged to obtain a clear supernatant layer with dissolved drug. After the suitable dilution, samples were analyzed using UV-Visible spectrophotometry. The partition coefficient of drug $\mathrm{K}_{\mathrm{o} / \mathrm{w}}$ and $\log \mathrm{P}$ were calculated using formula. 10

$\mathrm{Ko} / \mathrm{w}$

$=\frac{\text { Concentration of ion in octanol } \times \text { Volume of aquas phase }}{\text { Concentration on ion in water } \times \text { Volume of nonaquas phase }}$

\section{Thin Layer Chromatography}

The standard size TLC plates are used to improve the reproducibility. The plates are prepared with the help of silica gel, the thick layer of the mixture of silica gel is spreaded over the plates and the thickness of slurry is maintained about 1-1.5 mm. After preparation the plates were dried for 30 minutes in hot air oven at $110^{\circ} \mathrm{C}$. The melting point capillary is used to make spot. The capillary were filled by dilute solution and the solvent will allow drug solution for evaporation and again spot on same position. By this process a small or concentrated spot is applied. TLC chamber were used which contains ethyl acetate-methanolwater as solvent system (100:13.5:10) ratio. The prepared plates were placed in TLC chamber and then the chamber is closed with a lid. The plates will allow to making spots and after that remove the plates and dry with sunlight. After the successful drying the colored spots are detected by spraying $10 \%$ ethanolic $\mathrm{KOH}$ reagent and visualize under UV chamber at $365 \mathrm{~nm} .{ }^{11}$

The $\mathrm{R}_{\mathrm{f}}$ value of prepared plates were calculated by using the formula:

$$
R f=\frac{\text { Distance traveled by solute }}{\text { Distance traveled by solvent }}
$$

\section{FTIR Spectroscopy}

The functional groups of Barbaloin were determined by FTIR (Shimazadu IR Affinity-1) spectrophotometry. In the process of FTIR analysis the mixture of drug is added in a dry and fine powder of potassium bromide. Both the compounds were mixed in mortar and pestle and then compressed into a $\mathrm{KBr}$ disc in a hydraulic pressure of 75 $\mathrm{Kg} / \mathrm{cm}$. Each disc is scanned in the resolution of $2 \mathrm{~cm}$ for 20 times and then the required peaks were recorded. ${ }^{12}$

The excipients used in the formulation are also be examined by FTIR spectrophotometry. For the identification of characterstics peaks of excipients the above method was performed. The compatibility of drug with excipients was done on the basis of interpretation of some characterstics peaks of drug with particular excipients.

\section{UV-Visible Spectrophotometry:}

\section{Selection of analytical wavelength}

The standard stock solutions is used to make the suitable dilutions of drug and scanned under UV visible spectrometer from 200-600 $\mathrm{nm}$. The wavelength of Barbaloin was 
recorded by scanned spectrum and the absorbance maxima of drug were noted down. ${ }^{13}$

\section{Preparation of standard stock solution of Barbaloin}

$100 \mathrm{mg}$ of Barbaloin was weighed and transferred into 100 $\mathrm{ml}$ volumetric flask and dissolved in $10 \mathrm{~mL}$ of methanol as a (co-solvent), after that the flask was shaken and sonicate for 15 minutes and maintained the volume upto the mark with $6.8 \mathrm{pH}$ phosphate buffer. $10 \mathrm{ml}$ of solution was pipetted out from volumetric flask and then transferred it into another $100 \mathrm{ml}$ volumetric flask and the $100 \mathrm{~mL}$ volume was maintained with $6.8 \mathrm{pH}$ phosphate buffer upto the mark. The prepared concentration of stock solution was $100 \mu \mathrm{g} / \mathrm{mL}{ }^{13}$

\section{Selection of analytical concentration ranges}

A standard stock solution of Barbaloin (100 $\mu \mathrm{g} / \mathrm{mL}), 0.2,0.4$, $0.6,0.8,1.0 \mathrm{ml}$ of solution were pippeted out and transferred in to individual volumetric flask of $10 \mathrm{~mL}$. The volume of each volumetric flask was made upto $10 \mathrm{ml}$ with $6.8 \mathrm{pH}$ phosphate buffer. These concentration were made in the range of 2, 4, 6, $810 \mu \mathrm{g} / \mathrm{mL}$ respectively. ${ }^{14}$

For the identification of absorbance the selected wavelength of Barbaloin is used and a calibration curve of absorbance vs. concentration was plotted. Barbaloin follows the Lamberts Beer's law in the range of $2-10 \mu \mathrm{g} / \mathrm{mL}$.

\section{Preparation of calibration curve}

For the quantification of Barbaloin at different stages during the development and characterization of formulation, a calibration curve for drug was prepared in analytical solvent methanol as a (co-solvent) with $6.8 \mathrm{pH}$ phosphate buffer. For the estimation of calibration curve, accurately weighed quantity of Barbaloin (100 mg) was taken in $100 \mathrm{ml}$ volumetric flask and minimum amount of solvent (methanol) was added into volumetric flask and dissolved properly. Then, volume was made upto the mark with $6.8 \mathrm{pH}$ phosphate buffer. After making the volume upto the mark, the solution serves as standard stock solution. From the stock solution, working standard in the range of $2-10 \mu \mathrm{g} / \mathrm{mL}$ was prepared by suitable dilution with respective analytical solvents. Absorbance of each working standard was measured spectrophotometrically at the respective solvent. Obtained data were recorded by using MS Excel computer software and ion and absorbance. The extinction coefficient was calculated from the slope of regression line obtained from a plot between concentrations of drug. ${ }^{13,15}$

\section{Formulation Studies}

\section{Development of Hydrogel formulation}

For the development of hydrogel formulation the required quantity of all the excipients were used according to Table 1 and the drug used in each formulation was $0.1 \%$ concentration. Firstly, $50 \mathrm{ml}$ of distilled water was taken in a clean or dry beaker and then the gelling polymer, drug, ethanol, methyl paraben and propyl paraben were added in specific amount into the beaker and dispersed with the help of magnetic stirrer. After proper stirring kept the polymer aside at normal room temperature for 24 hours swelling. After 24 hours, the required quantities of glycerine, propylene glycol, Transcutol $\mathrm{P}$ were added and qs distilled water was used to make up the volume. In last, the $\mathrm{pH}$ of formulation is adjusted up to 5.5 with the help triethanolamine.

Table 1: Formulation Table of Hydrogel

\begin{tabular}{|c|c|c|c|c|c|c|c|c|c|c|}
\hline $\begin{array}{c}\text { Excipients } \\
(\% \mathbf{w} \text { /w) }\end{array}$ & F1 & F2 & F3 & F4 & F5 & F6 & F7 & F8 & F9 & F10 \\
\hline Carbopol 934 & 1 & 1.5 & 2 & 1 & 1 & 1.5 & - & - & 1 & 1.5 \\
\hline Xanthan Gum & - & - & - & 0.5 & 1 & 0.5 & - & - & - & - \\
\hline Carbopol 940 & - & - & - & - & - & - & 1.5 & 2 & - & - \\
\hline Carbopol 71G NF & - & - & - & - & - & - & - & - & 0.5 & 0.5 \\
\hline Glycerine & 5 & 5 & 5 & 5 & 5 & 5 & 5 & 5 & 5 & 5 \\
\hline Propylene Glycol & 2.5 & 2.5 & 2.5 & 2.5 & 2.5 & 2.5 & 2.5 & 2.5 & 2.5 & 2.5 \\
\hline Ethanol & 2.5 & 2.5 & 2.5 & 2.5 & 2.5 & 2.5 & 2.5 & 2.5 & 2.5 & 2.5 \\
\hline Transcutol P & 0.2 & 0.2 & 0.2 & 0.2 & 0.2 & 0.2 & 0.2 & 0.2 & 0.2 & 0.2 \\
\hline Methyl Paraben & 0.2 & 0.2 & 0.2 & 0.2 & 0.2 & 0.2 & 0.2 & 0.2 & 0.2 & 0.2 \\
\hline Propyl Paraben & 0.1 & 0.1 & 0.1 & 0.1 & 0.1 & 0.1 & 0.1 & 0.1 & 0.1 & 0.1 \\
\hline Distt. Water & $\mathrm{qs}$ & $\mathrm{qs}$ & $\mathrm{qs}$ & $\mathrm{qs}$ & $\mathrm{qs}$ & $\mathrm{qs}$ & $\mathrm{qs}$ & $\mathrm{qs}$ & $\mathrm{qs}$ & $\mathrm{qs}$ \\
\hline
\end{tabular}

\section{Evaluation of Gel}

\section{Physical Appearance}

Physical appearances of the formulated hydrogels were evaluated by visual perception and with the help of simple microscope. The sample was placed on glass slide with the help of cover slip. Then the slide was observed under microscope and the physical appearances of gels were studied.

\section{Measurement of $\mathrm{pH}$}

A digital $\mathrm{pH}$ meter is used to find out the $\mathrm{pH}$ of gel formulations. In a clean beaker with $50 \mathrm{~mL}$ of distilled water the $1 \mathrm{gm}$ of gel were dissolved properly and kept it in a beaker for 2 hr's. The $\mathrm{pH}$ of each formulation was investigated in triplicate and the average reading was recorded. 16 


\section{Viscosity}

Viscosity of gel was measured by use of Brookfield viscometer (LVDV-II+Pro). The sufficient quantity of Barbaloin gel was filled in sample holder separately. The height of the gel was filled in the sample holder should sufficiently allow to dip the spindle. Viscosities of the gels were recorded by adjusting the rotating speed of the spindle at 2.5 rpm. ${ }^{17}$

\section{Drug Content}

From each formulation $1 \mathrm{gm}$ of gel was taken in a $100 \mathrm{~mL}$ volumetric flask and made up to volume by $\mathrm{pH} 6.8$ phosphate buffer and shaken well to dissolve the active constituents in solvent. The solution was sonicated for few minutes and filtered it with the help of Whatman filter paper. After that, $0.1 \mathrm{~mL}$ of the filtrate was pipetted out and diluted upto $10 \mathrm{~mL}$ with $\mathrm{pH} 6.8$ buffer. The content of active constituents was estimated spectro photometrically by using $268 \mathrm{~nm} \lambda \max$ of Barbaloin. The drug content present in the formulation was identified with the help of linear regression analysis of calibration curve. ${ }^{18}$

\section{Swelling Index}

For the determination of swelling index we take 1gm quantity of gel and then it was filled in a clean and dry (50 $\mathrm{mL}$ ) beaker, the beaker hold $10 \mathrm{~mL}$ of distilled water. The samples were retained in a beaker for period of time and then after some time kept out the gel from beaker and put into a dry or clean place for some times and weight it again to calculate and find out how much percent of the gel was swelled ${ }^{19}$.

We can calculate the swelling index by applying this formula:

$$
\begin{gathered}
\text { Swelling Index }(S W) \%=\left[\frac{(W t-W o)}{W o}\right] \times 100 \\
\text { Where, }(\mathrm{SW}) \%=\% \text { age swelling } \\
\mathrm{W}_{\mathrm{t}}=\text { Swollen gel weight after time }(\mathrm{t}) \\
\mathrm{W}_{\mathrm{o}}=\text { Initial weight of gel }
\end{gathered}
$$

\section{Spreadability}

For the identification of spreadability of gel formulations the spreadability apparatus which contain two glass slides of $(20 \times 20 \mathrm{~cm})$ is used. We take $1 \mathrm{gm}$ of gel and placed it on one slide. The second slide was placed over the gel and due to this the gel was pressed and spreaded between two glass slides. After that, the $100 \mathrm{gm}$ of weight was placed over the top slide to press the gel freely and it will give us thin layer. The weight was removed and 20 gm weight was tied to the upper slide carefully. The total time taken by top slide and the traveled distance of slide were examined.20 The whole procedure was performed three times and the average time of three trials was used for further calculations.

The following formula was used to find out the spreadability:

$$
\begin{gathered}
S=\frac{\mathrm{m} \times \mathrm{l}}{\mathrm{t}} \\
\text { Where, } \mathrm{S}=\text { spreadability } \\
\mathrm{m}=\text { weight tied on top slides } \\
\mathrm{l}=\text { length of the glass slide } \\
\mathrm{t}=\text { time in sec. }
\end{gathered}
$$

\section{Homogeneity}

All the formulation of gels was stored in container and they are visually observed to identify for their appearance of any type of aggregates in the gel formulations.

\section{Grittiness}

The prepared formulations of gel were microscopically observed to find out the presence of any unwanted particulate. All the formulations of gel were determined for fulfill the obligation of free from unwanted particulate matter.

\section{Microscopic Evaluation}

The prepared formulations of gel were microscopically evaluated to check the presence of lump. This was done by taking few quantity of gel and kept it on a glass slide and observes under microscope.

\section{Effect of Gelling agents}

For the formulation and characterization of hydrogel we had selected four polymers as gelling agents which include carbolpol-934, carbolpol-940, Xanthan gum, and carbopol71G-NF. All these polymers were used in different concentration in the range of $0.5-2 \%$. Some of these are used in combination with each other and some were used as single gelling agent. The changes in each formulation help us to understand the behavior of gelling agents and also helpful to find out their effect in the formulation of hydrogels. They were further evaluated to know their appearance, spreadability, changes in viscosity, and swelling index etc.

\section{In Vitro drug release study}

Franz diffusion cell was used to find out the invitro drug release of gel formulations. In receptor compartment pH 6.8 phosphate buffer was filled. Cellophane membrane was used as dialysis membrane. The membrane was dip inside the phosphate buffer for overnight swelling and on the donor cell compartment the membrane with gel was tied carefully. Such that the cellophane membrane was in intimate contact with the release surface of the formulation in the donor compartment. The pH 6.8 phosphate buffer was added to a donor compartment attached on the cell. A weighed quantity of formulation equivalent to $1 \mathrm{~g}$ of gel was taken on to the cellophane membrane and was immersed slightly in receptor media by continuously stirring. The whole experiment is done at $37 \pm 1{ }^{\circ} \mathrm{C}$. During the process an equal volume of sample $(5 \mathrm{~mL})$ was withdrawn at several intervals of time $(1,2,3,4,5,6,7$ and $8 \mathrm{hr})$ and during each withdrawn the donor compartment was replaced with equal volume of phosphate buffer. All the samples were estimated spectrophotometrically at $268 \mathrm{~nm}$. The cumulative percent release was calculated for each time (in hr) interval. ${ }^{21}$ After that the In Vitro drug release of selected formulations was interpreted with Zero order, First order, Higuchi and Korsmeyer Peppas kinetic models.

\section{RESULTS AND DISCUSSION}

\section{Preformulation Study of Barbaloin}

\section{Physical Description}

The Barbaloin drug is obtained in Lemon yellow colored powder.

\section{Determination of Melting Point}

The melting point of Barbaloin was found to be $148^{\circ} \mathrm{C}$.

\section{Determination of $\mathbf{p H}$}

The $\mathrm{pH}$ of the Barbaloin was found to be 4.5-5.6. 


\section{Partition Coefficient}

The standard $\log \mathrm{P}$ value of Barbaloin is 0.73 respectively and the observed value of Barbaloin was found to be 0.71 . The $\log \mathrm{P}$ value suggests that, Barbaloin is hydrophilic in nature.

\section{Thin Layer Chromatography}

TLC characterization of Barbaloin was performed by using ethyl acetate-methanol-water (100:13.5:10) in mobile phase and $10 \%$ ethanolic reagent as a spraying reagent to detect the colour of spot. By performing the whole TLC experiment the colour of spot and calculated $R_{f}$ value of prepared plate was given in Table 2:

Table 2: TLC Characterization of Barbaloin.

\begin{tabular}{|c|c|c|c|c|}
\hline Drug & Mobile Phase & Spraying Reagent & Color of Spot & $\mathbf{R f}$ \\
\hline Barbaloin & $\begin{array}{c}\text { ethyl acetate:methanol:water } \\
(100: 13.5: 10)\end{array}$ & $10 \%$ ethanolic KOH & Red & 0.46 \\
& & & & \\
\hline
\end{tabular}

\section{FTIR Spectroscopy of Barbaloin}

FTIR of Barbaloin is considered at the range of 4000-400-1. FTIR spectra of Barbaloin shows the characterstics peak at $3677.45,3568.46$ due to $\mathrm{OH}, 2991.75,2834.87,2782.44$ due to $\mathrm{CH}$ stretch in alkane, 1600.02 due to $\mathrm{CO}$ (carbonyl stretching), 1532.51 due to $\mathrm{C}=\mathrm{C}$ (bending), 774.45, 736.84 due to $\mathrm{CH}$ (alkene bending) and 1188.20, 1171.81, 1166.02 due to ether medium. The ranges of peaks in the IR spectrum verify the occurrence of various functional groups as compare to the standard spectrum in Figure 1 (a), which confirm the purity of the Barbaloin. In the IR spectrum of Barbaloin with excipients used in the preparation of formulations, we examined that the observed frequencies of Barbaloin are in the standard frequencies range in Figure 1 (b) with their characterstics functional groups.

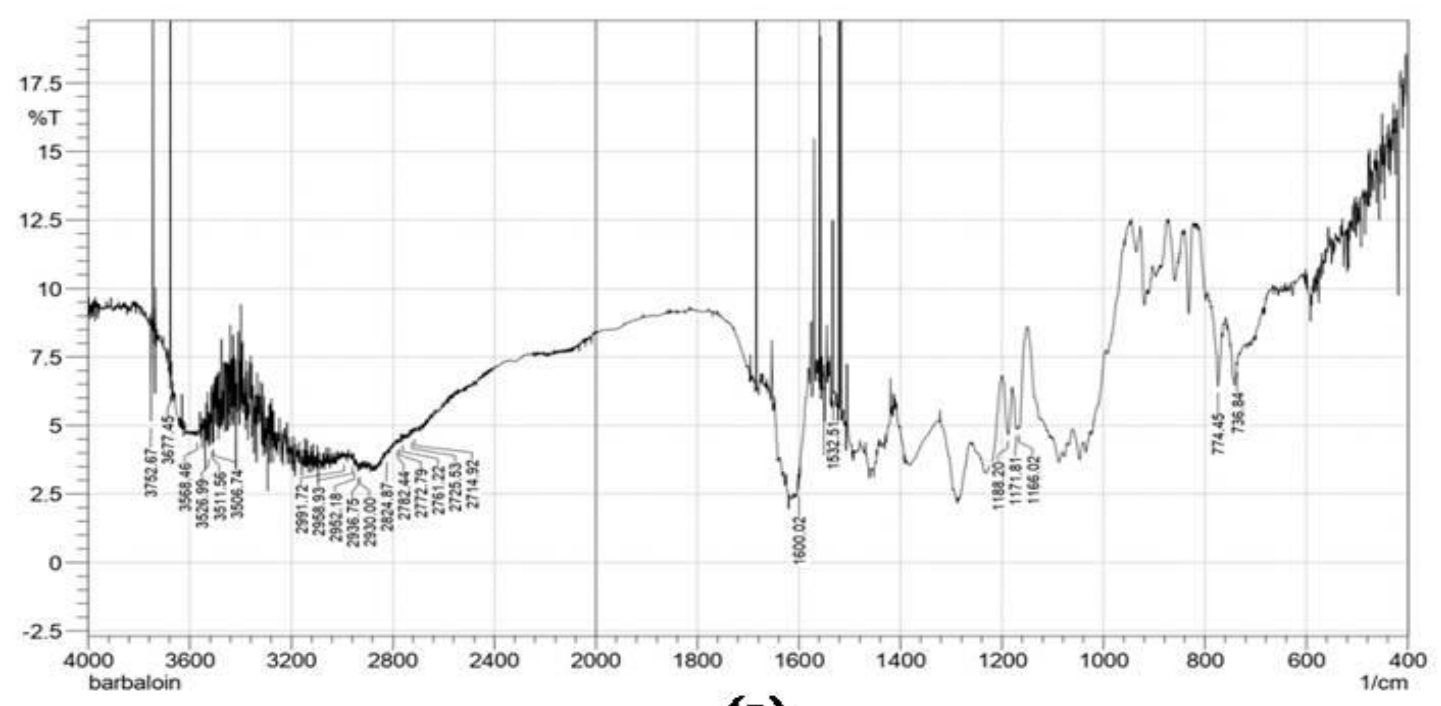

(a)

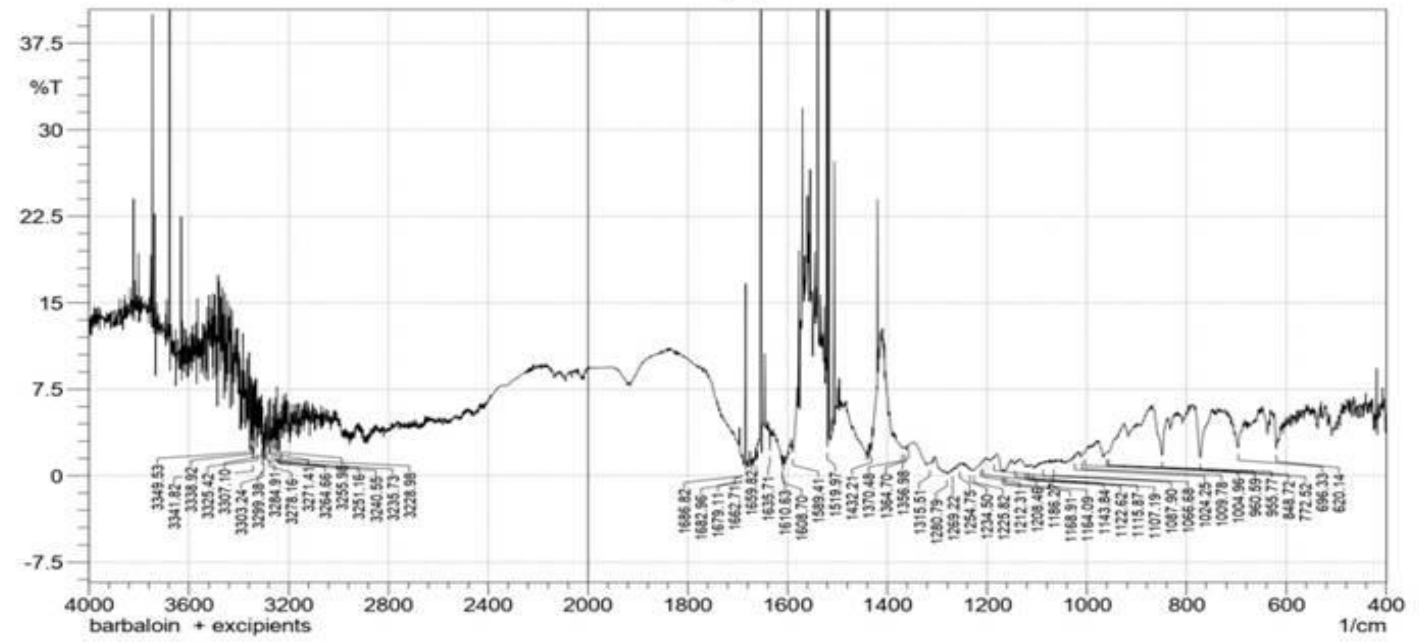

(b)

Figure 1 (a): IR Spectrum of Barbaloin, (b) IR Spectrum of Drug with Excipients Used in the preparation of Formulations. 


\section{UV-Visible Spectrophotometry of Barbaloin}

\section{Selection of analytical wavelength}

The wavelength of Barbaloin was carried out by preparing the dilutions at different concentration and the $\lambda_{\max }$ of Barbaloin was selected as $268 \mathrm{~nm}$ for final results. The spectrum has been shown in Figure 2 (a) respectively.

\section{Linearity Curve of Barbaloin}

The linearity of Barbaloin was found at the concentration range of $2-10 \mu \mathrm{g} / \mathrm{mL}$ at $268 \mathrm{~nm}$. The $\mathrm{R}^{2}$ value was at 0.999 respectively. The linearity curve was made with concentration $(\mu \mathrm{g} / \mathrm{mL})$ on $\mathrm{X}$ axis and Absorbance on $\mathrm{Y}$ axis in Figure 2 (b).

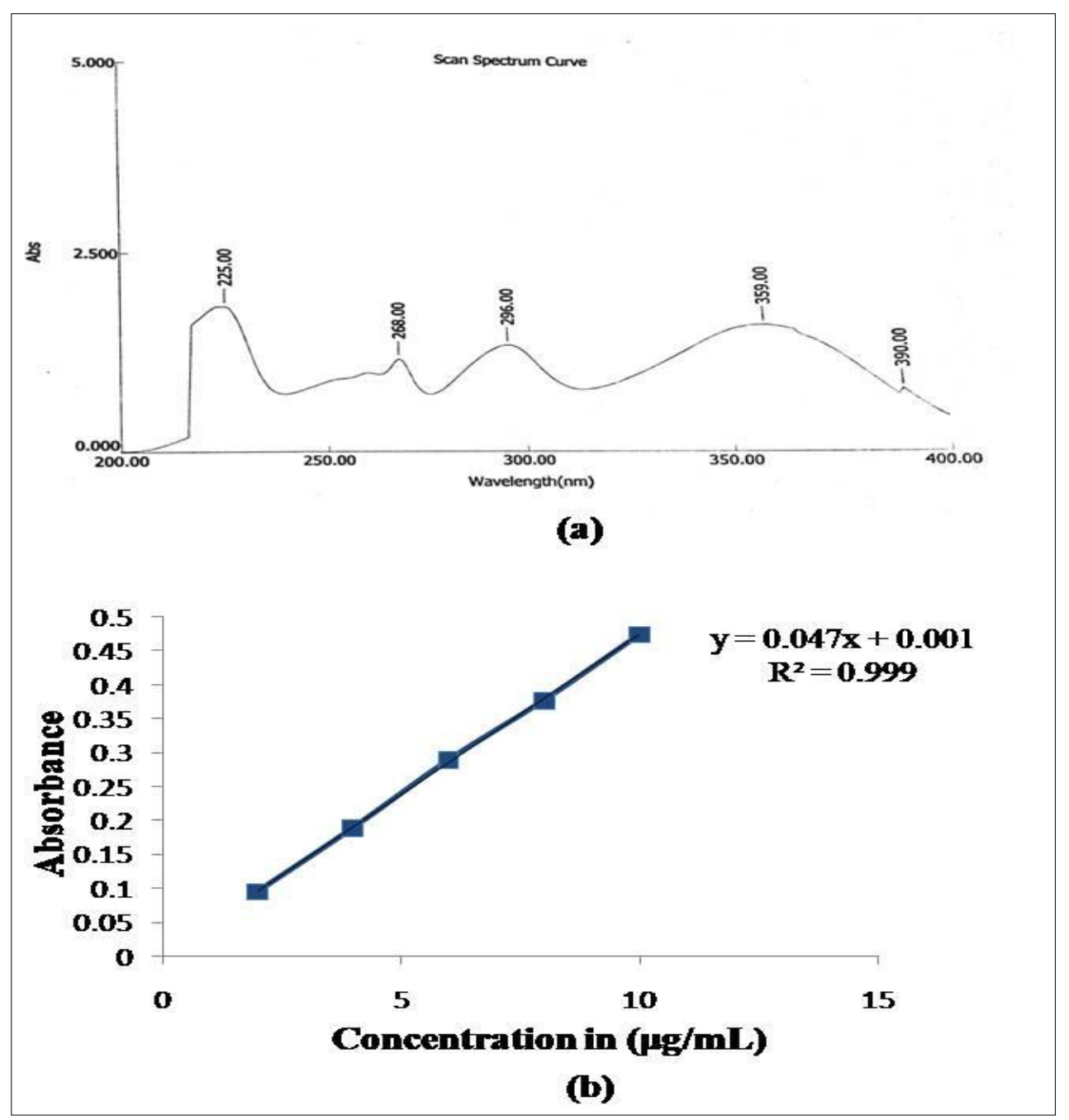

Figure 2: (a) UV-Vis Spectrum of Barbaloin (8 $\mu \mathrm{g} / \mathrm{mL}$ ), (b) Linearity Curve of Barbaloin at $268 \mathrm{~nm}$

Table 3: Result of Linearity Curve of Barbaloin.

\begin{tabular}{|l|c|c|}
\hline S.No & $\begin{array}{c}\text { Concentration } \\
(\boldsymbol{\mu g} / \mathbf{m L})\end{array}$ & $\begin{array}{c}\text { Absorbance at } \\
\mathbf{2 6 8} \mathbf{~ n m}\end{array}$ \\
\hline $\mathbf{1 .}$ & 2 & 0.095 \\
\hline $\mathbf{2 .}$ & 4 & 0.189 \\
\hline $\mathbf{3 .}$ & 6 & 0.289 \\
\hline $\mathbf{4 .}$ & 8 & 0.377 \\
\hline $\mathbf{5 .}$ & 10 & 0.474 \\
\hline
\end{tabular}

\section{Characterization of Gel formulation}

The gel formulation of Barbaloin was prepared successfully. For the evaluation parameter of gel formulation the different type of tests are performed (appearance, homogeneity, grittiness, $\mathrm{pH}$, spreadability, microscopic evaluation, viscosity, drug content, swelling index etc.) were performed to identify and get the best optimized formulations from (F1F10). The optimized formulations were used in our research work. 
Table 4: Evaluation parameters of Barbaloin gel formulations for psoriasis treatment

\begin{tabular}{|c|c|c|c|c|c|c|c|c|c|c|c|}
\hline 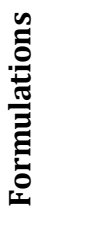 & 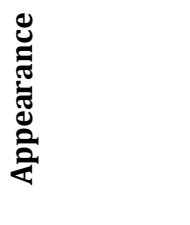 & 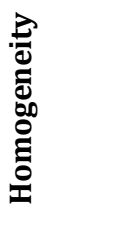 & 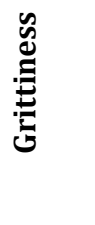 & 竞 & 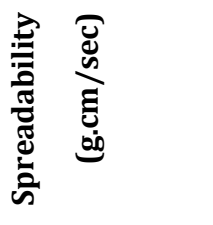 & 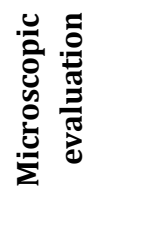 & 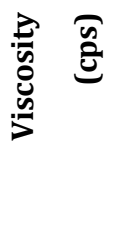 & 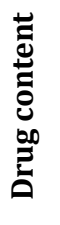 & 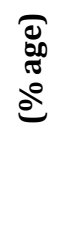 & 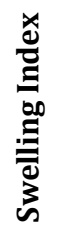 & 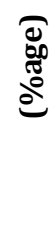 \\
\hline F1 & Light Yellow & +++ & No & $5.5 \pm 0.06$ & $23.008 \pm 0.0218$ & No Lumps & 37325 & & 96.9 & & 63 \\
\hline F2 & Light Yellow & ++++ & No & $5.6 \pm 0.07$ & $18.035 \pm 0.0325$ & No Lumps & 41500 & & 98.2 & & 77 \\
\hline F3 & Yellow & + & Yes & $5.3 \pm 0.06$ & $13.062 \pm 0.0175$ & Lumps & 47248 & & 93.6 & & 89 \\
\hline F4 & Light yellow & ++++ & No & $5.4 \pm 0.06$ & $22.038 \pm 0.0316$ & No Lumps & 42257 & & 99.2 & & 75 \\
\hline F5 & Yellow & + & Yes & $5.7 \pm 0.07$ & $14.023 \pm 0.0213$ & Lumps & 49582 & & 94.7 & & 81 \\
\hline F6 & Yellow & +++ & No & $5.9 \pm 0.03$ & $12.071 \pm 0.0181$ & No Lumps & 46241 & & 95.2 & & 83 \\
\hline F7 & Light yellow & ++++ & No & $5.3 \pm 0.07$ & $19.035 \pm 0.0287$ & No lumps & 43523 & & 98.6 & & 78 \\
\hline F8 & Yellow & +++ & Yes & $5.4 \pm 0.06$ & $12.076 \pm 0.0132$ & Lumps & 52429 & & 96.8 & & 90 \\
\hline F9 & Yellow & ++ & No & $5.8 \pm 0.007$ & $16.037 \pm 0.0142$ & No Lumps & 36495 & & 94.4 & & 69 \\
\hline F10 & Light Yellow & ++++ & No & $5.5 \pm 0.09$ & $18.024 \pm 0.0253$ & No Lumps & 41422 & & 98.2 & & 74 \\
\hline
\end{tabular}

Note: *Average of three trials,

++++ very good; + + + good; + + average; + poor

\section{Effects of Gelling agents in Formulations}

\section{Effect of Carbopol 934}

In the preparation of topical formulation of hydrogels we are using carbopol 934 in the concentration range of F1 (1\%), F2 (1.5\%), F3 (2\%). The physical appearance of these formulation show good color properties from light yellow to yellow. The viscosities were high in formulation F3 as compare to $F 1$ and F2, because by increase in the concentration of polymer the viscosity of gel was also increased. The swelling property of carbopol 934 is depending on the concentration of gelling agent, the swelling property of F2 and F3 is more than F1. The swelling of gel formulation were increase as the concentration of carbopol 934 increases. At low concentration of polymer in F1 spreadability is increased, while F2 and F3 will gradually decrease in the spreadability. From all these three formulation the physical appearance of F2 was good, and it will show impressive results by microscopic evaluation.

\section{Effect of Carbopol 934 in Combination with Xanthan Gum}

Xanthan gum is used to prepare the hydrogel in combination with carbopol 934. Both the polymers are used in various concentration ranges in hydrogel formulation, F4 (carbopol 934-1\%/Xanthan gum-0.5\%), F5 (carbopol 934-1\%/Xanthan gum-1\%), F6 (carbopol 934-1.5\%/Xanthan gum-0.5\%) were used. The physical appearances of F4, F5 and F6 were identified at light yellow to yellow in color gel. By increasing the concentration of Xanthan gum in combination with carbopol 934 it will increase their viscosity and quite decrease in spreadability of formulation F5 and F6. The swelling behavior of all three formulations was different, while higher percentage of swelling in F5 and F6 was observed, this is because of the high concentration of both the gelling agents. By combining F4, F5 and F6 formulation F4 show good results of physical appearance as well as good viscosity, spreadability and swelling property.

\section{Effect of Carbopol 940}

Carbopol 940 is used in formulation F7 (1.5\%) and F8 (2\%) as a single gelling agent. By comparing the results of this gelling agent at different concentration we will find that formulation F8 show higher range of viscosity and gradually decrease in their spreadability. The swelling property of F8 is higher than that of F7. At the concentration range of $1.5 \%$ in F7 the viscosity and spreadability was quite good as compare to F8. By comparing carbopol 940 as a single gelling agent with F2 and F3 (1.5-2\% carbopol 934), we will find that carbopol 940 in the concentration of $1.5 \%$ had good physical appearance by microscopical evaluation and the consistency of F7 formulation was good.

\section{Effect of Carbopol 934 in combination with Carbopol 71G NF}

Carbopol 71G NF in same concentration range was used in combination with different concentration of carbopol 934. In formulation F9 (Carbopol-1\% /Carbopol 71G NF-0.5\%) and F10 (carbopol 934-1.5\%/carbopol 71G NF-0.5\%) were used. All these three formulation were made by varying the concentration range of carbopol 934 and same equal concentration of carbopol $71 \mathrm{G} \mathrm{NF}$ is added in both the formulations. The viscosity of F9 is less as compare to F10, and a minute change was observed in the spreadability of F9. Both these formulations show quite similar swelling property, but difference is observed in the viscosity or spreadability. By physical evaluation the consistency and appearance of F10 formulation was good and it will show good results as compare to F9.

According to the comparative study of the formulations from F1-F10 it has to be identifying that the formulation F2, F4, F7 and F10 show good evaluation results as compare to other formulations. Furthermore, these four optimized formulation are selected for the higher evaluation studies (In Vitro drug release) on the basis of their optimum viscosity, spreadability, swelling property as well as their good physical appearances. 


\section{In Vitro drug release study}

The selected formulations with code F2, F4, F7 and F10 are experimented by In Vitro to identify the drug release of selected hydrogel formulation. All the selected formulations are further evaluated by kinetic study and the four kinetic models are used (zero order, first order, higuchi, korsmeyer Peppas). The obtained results of released drug are tabulated and represented graphically in Figure 3.

Table 5: In Vitro Drug Release study from Selected Formulations

\begin{tabular}{|r|r|r|r|r|r|}
\hline S.No. & $\begin{array}{r}\text { TIME } \\
\text { (hr's) }\end{array}$ & F2 & F4 & F7 & F10 \\
\hline $\mathbf{1 .}$ & 0 & 0 & 0 & 0 & 0 \\
\hline $\mathbf{2 .}$ & 1 & 17.34 & 10.35 & 9.32 & 14.63 \\
\hline $\mathbf{3 .}$ & 2 & 29.23 & 17.32 & 15.21 & 27.31 \\
\hline $\mathbf{4 .}$ & 3 & 40.2 & 25.31 & 23.39 & 40.59 \\
\hline $\mathbf{5 .}$ & 4 & 55.41 & 33.81 & 31.2 & 54.27 \\
\hline $\mathbf{6 .}$ & 5 & 66.32 & 46.32 & 40.28 & 67.21 \\
\hline $\mathbf{7 .}$ & 6 & 74.12 & 54.44 & 48.65 & 76.65 \\
\hline $\mathbf{8 .}$ & 7 & 81.42 & 62.23 & 57.11 & 84.66 \\
\hline $\mathbf{9 .}$ & 8 & 92.25 & 69.53 & 65.54 & 89.51 \\
\hline
\end{tabular}

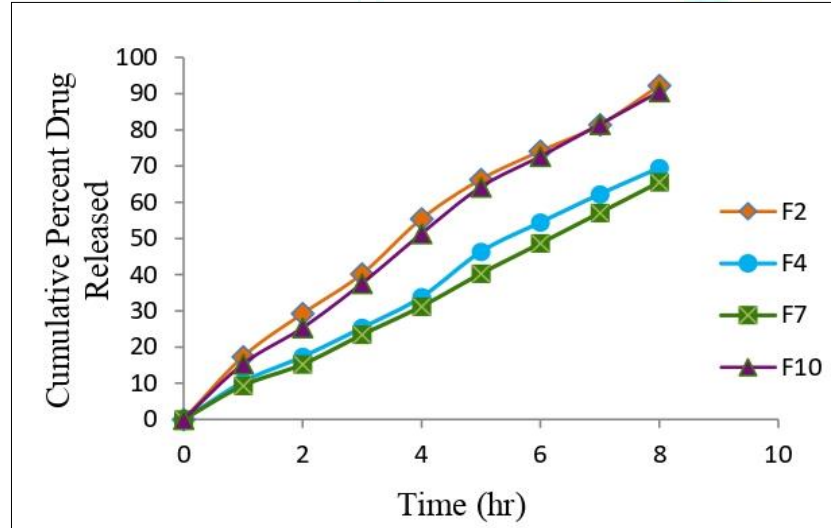

(a) Zero order



(c) Higuchi

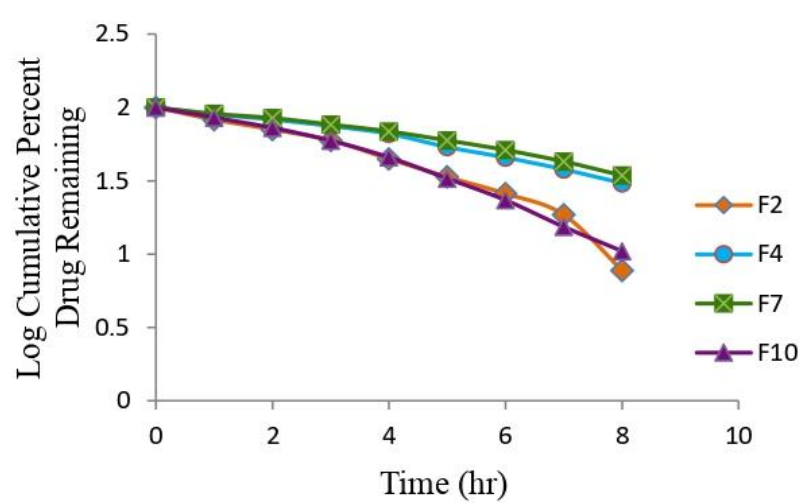

(b) First order

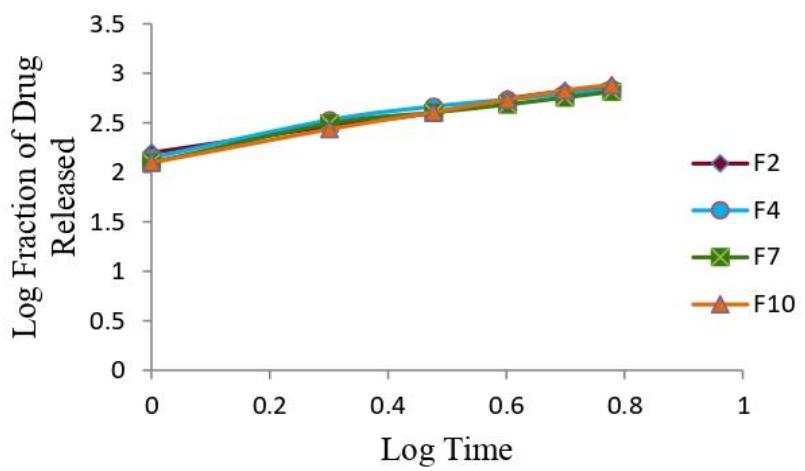

(d) Korsmeyer Peppas

Figure 3: (a) Zero order release profile, (b) First order release profile, (c) Higuchi release profile, (d) Korsmeyer Peppas release profile. 
Table 6: Kinetics of In Vitro Release from Selected Formulations

\begin{tabular}{|c|c|c|c|c|c|}
\hline Formulations & Zero order & First order & Higuchi & \multicolumn{2}{|c|}{ Korsmeyer } \\
\hline Code & $\mathbf{R}^{\mathbf{2}}$ & $\mathbf{R}^{\mathbf{2}}$ & $\mathbf{R}^{\mathbf{2}}$ & $\mathbf{N}$ & $\mathbf{R}^{\mathbf{2}}$ \\
\hline F2 & 0.987 & 0.930 & 0.956 & 0.876 & 0.997 \\
\hline F4 & 0.997 & 0.975 & 0.912 & 0.904 & 0.958 \\
\hline F7 & 0.998 & 0.970 & 0.904 & 0.830 & 0.981 \\
\hline F10 & 0.993 & 0.971 & 0.948 & 0.9 & 0.997 \\
\hline
\end{tabular}

For the identification of release mechanism the drug release data were explored by kinetic models. The best fit of kinetic model is noticed by observing the $R^{2}$ value of each formulation. In which the highest $\mathrm{R}^{2}$ coefficient was observed by both Higuchi and first order models followed by zero order model which showed the drug release by diffusion mechanism.

Diffusion, swelling and erosion are the three main important mechanisms for controlled and sustained release formulations. The release of drug by polymeric system is generally by diffusion and best described by fickian diffusion. The formulations which include the swelling of polymers, relaxations of polymer chain, imbition of water causing polymers by allowing to swell and change their state from initial glassy to rubbery. Appropriate swelling and significant degree of expansion takes place will lead to moving the diffusion boundaries, complicating the solution of Fick's second law of diffusion.

The $\mathrm{n}$ value of all formulations was (F2-0.8), (F4-0.9), (F70.8 ) and (F10-0.9). From these values all the formulations showed non fickian drug release mechanism shown in Table 6. Therefore, from the above release study parameters formulation F2 and F10 show the best optimized release characterstics as compare to the selected optimized formulations F4 and F7.

\section{CONCLUSION}

Psoriasis is a chronic inflammatory skin condition and immune mediated ailment. The prevalence of psoriasis occurs worldwide. In the treatment of skin diseases the best method for the delivery of drugs is through topical route. Hydrogel formulations of Barbaloin were prepared with an objective of increasing the skin permeation of drugs and effective to improve the efficacy of topical application for psoriasis. Multiple polymers in single and with combination were used to prepare the formulations of hydrogel. Hydrogels composed of carbopol 934, Xanthan gum, carbopol 940 and carbopol 71G NF polymers, glycerine, propylene glycol, ethanol, Transcutol $\mathrm{P}$ and triethanolamine were prepared desirable gel characterstics good efficacy of the topical delivery of Barbaloin. The prepared formulations were evaluating for their physical appearance, $\mathrm{pH}$, viscosity, spreadability, grittiness, homogeneity, swelling index and drug content. In our study we find that formulation F2, F4, F7 and F10 show good gelling properties with concern to the above evaluation parameters. By comparing the all formulations of hydrogel they are further evaluated for in vitro drug release study, in which the formulation F2 and F10 showed highest release in 8 hr's. The kinetics of invitro drug release showed that, the F2, F4, F7 and F10 formulations had good release kinetics and showed non fickian drug release as the $\mathrm{n}$ value was between 0.8 to 0.9 . From these release parameters, formulations $\mathrm{F} 2$ and F4 showed highest release of Barbaloin in 8 hr's. These results suggest the improvement of efficacy of topical gel for the treatment of psoriasis. The enhanced efficacy of Barbaloin gel is due to increased penetration of drugs from hydrogel than conventional formulations.

\section{ACKNOWLEDGEMENT}

The author wishes to acknowledge Department of Pharmaceutics, Laureate Institute of Pharmacy, Jawalamukhi, Himachal Pradesh (176031), for providing required facilities in this research work.

\section{CONFLICTS OF INTEREST}

None Declared

\section{REFERENCES}

1. Menter A, Korman NJ, Elmets CA, Feldman SR, Gelfand JM, Gordon KB, Gottlieb A, Koo JY, Lebwohl M, Leonardi CL, Lim $\mathrm{HW}$, "Guidelines of care for the management of psoriasis and psoriatic arthritis: section 6" Journal of the American Academy of Dermatology, 2011; 65(1):137-74.

2. Shrivastav S, Sindhu R, Kumar S, Kumar P, "Anti-psoriatic and phytochemical evaluation of Thespesia populnea bark extracts" Int J Pharm Sci, 2009; 1(1)

3. Rapp SR, Feldman SR, Exum ML, Fleischer Jr AB, Reboussin DM, "Psoriasis causes as much disability as other major medical diseases" Journal of the American Academy of Dermatology, 1999; 41(3):401-7.

4. Griffiths CE, Vander Walt JM, Ashcroft DM, Flohr C, Naldi L, Nijsten T, Augustin M, "The global state of psoriasis disease epidemiology: a workshop report" British Journal of Dermatology, 2017; 177(1):4-7.

5. Singh KK, Tripathy $S$, "Natural treatment alternative for psoriasis: a review on herbal resources" Journal of Applied Pharmaceutical Science, 2014; 4(11):114-21.

6. Patel DK, Patel K, Tahilyani V, "Barbaloin: a concise report of its pharmacological and analytical aspects" Asian Pacific journal of tropical biomedicine, 2012; 2(10):835-8.

7. Sánchez M, González-Burgos E, Iglesias I, Gómez-Serranillos MP, "Pharmacological update properties of Aloe vera and its major active constituents" Molecules, 2020; 25(6):1324

8. Tabata Y, "Biomaterial technology for tissue engineering applications" Journal of the Royal Society interface, 2009; 6(3):311-24.

9. McGhie AR, Chiu J, Fair PG, Blaine RL, "Thermogravimetric apparatus temperature calibration using melting point standards" Thermochimica acta, 1983; 67(2-3):241-50.

10. Bannan CC, Calabró G, Kyu DY, Mobley DL, "Calculating partition coefficients of small molecules in octanol/water and cyclohexane/water" Journal of chemical theory and computation, 2016; 12(8):4015-24.

11. Bele AA, Khale A, "An overview on thin layer chromatography" International Journal of Pharmaceutical Sciences and Research, 2011; 2(2):256.

12. Dent G, "Preparation of Samples for IR spectroscopy as $\mathrm{KBr}$ disks" Internet Journal of Vibrational Spectroscopy, 1996; 1:12 .

13. Rote AR, Kumbhoje PA, Bhambar RS, "UV-visible spectrophotometric simultaneous estimation of paracetamol 
and nabumetone by AUC method in combined tablet dosage form" Pharmaceutical methods, 2012; 3(1):40-3.

14. Ahmed S, Mustaan N, Sheraz MA, un Nabi SA, Ahmad I, "Validation of a UV spectrometric method for the assay of tolfenamic acid in organic solvents" Journal of pharmaceutics, 2015.

15. Behera S, Ghanty S, Ahmad F, Santra S, Banerjee S, “UV-visible spectrophotometric method development and validation of assay of paracetamol tablet formulation" J Anal Bioanal Techniques, 2012; 3(6):151-7.

16. Queiroz MB, Marcelino NB, Ribeiro MV, Espindola LS, Cunha FR, Silva MV, "Development of gel with Matricaria recutita L. extract for topic application and evaluation of physicalchemical stability and toxicity" Lat. Am. J. Pharm, 2009; 28(4):574-9.

17. Nayak SH, Nakhat PD, Yeole PG, "Development and evaluation of cosmeceutical hair styling gels of ketoconazole" Indian journal of pharmaceutical sciences, 2005; 67(2):231.
18. Nandgude T, Thube R, Jaiswal N, Deshmukh P, Chatap V, Hire $\mathrm{N}$, "Formulation and evaluation of $\mathrm{pH}$ induced in-situ nasal gel of salbutamol sulphate" International journal of pharmaceutical sciences and nanotechnology, 2008; 1(2):17783.

19. Lee Y, Kim DN, Choi D, Lee W, Park J, Koh WG, "Preparation of interpenetrating polymer network composed of poly (ethylene glycol) and poly (acrylamide) hydrogels as a support of enzyme immobilization" Polymers for Advanced Technologies, 2008; 19(7):852-8.

20. Jain BD, "Formulation development and evaluation of Fluconazole gel in various polymer bases" Asian Journal of Pharmaceutics, 2016; 1(1).

21. Kumar L, Verma R, "In vitro evaluation of topical gel prepared using natural polymer" International journal of drug delivery, 2010; 2(1). 